\title{
Antigenic Modulation and Turnover in Human Neutrophils
}

\author{
Sigmund A. Weitzman, Mary C. Desmond, and Thomas P. Stossel, \\ Medical Oncology Unit, Massachusetts General Hospital, \\ Boston, Massachusetts 02114
}

\begin{abstract}
A B S T RACT Turnover of membrane constituents appears important in many biologic processes. We studied this process in neutrophils by immunologic methods. The capacity of neutrophils to recognize other neutrophils coated with antibodies against membrane antigens was used to determine the changes that occur after attachment of the antibody to the neutrophil membrane. Neutrophils were sensitized for $30 \mathrm{~min}$ at $22^{\circ} \mathrm{C}$ with antibodies from three patients with antineutrophil autoantibodies. The sensitized neutrophils were recognized by normal neutrophils, which responded with an increase in glucose oxidation. If, after sensitization, the sensitized neutrophils were not immediately exposed to normal neutrophils, but instead were incubated at $37^{\circ} \mathrm{C}$ for varying times, the capacity to elicit a recognition response decayed and was gone by $30 \mathrm{~min}$. Additionally, the capacity of the cells to be resensitized by reexposure to antibody also decayed during this period. However, after further incubation at $37^{\circ} \mathrm{C}$, the neutrophils recovered the capacity to become sensitized; and this recovery was not inhibited by the addition of cycloheximide. Control incubations with normal immunoglobulin (Ig)G did not elicit a recognition response. The decay in recognition response was temperature dependent. Direct immunofluorescent studies with fluorescein-conjugated antineutrophil IgG revealed
\end{abstract}

Some of this material was presented in preliminary form at the Eastern Regional Meetings, Federation for Clinical Research, Newton, Mass., 21 October 1978; and at the 21st Annual Meeting of the American Society of Hematology, New Orleans, La., 4 December 1978.

Received for publication 22 March 1979 and in revised form 27 April 1979. that the antibodies were cleared by aggregation and endocytosis. We conclude that: $(a)$ neutrophils clear antibody from the cell surface by a temperature-dependent mechanism; $(b)$ antigenicity is cleared concomitantly; $(c)$ the mechanism of clearance involves internalization; and $(d)$ with time, antigenicity reappears on the cell surface.

\section{INTRODUCTION}

The binding of antibodies to human blood cells can accelerate the clearance of these cells from the blood stream by mononuclear phagocytes. The increased clearance causes clinical diseases, such as autoimmune hemolytic anemia, thrombocytopenic purpura, and autoimmune neutropenia $(1,2)$. Only elution or interaction with phagocytic cells can remove a coating of antibody from erythrocytes. Neutrophils, on the other hand, being phagocytes, have the capacity to process cell-bound antibody in an active way. This report illustrates that normal neutrophils internalize cell-bound antibody and that the antigen against which the antibody is directed is lost concomitantly. Subsequently, the antigen reappears on the cell surface. These phenomena indicate the existence of membrane antigen turnover in mature human neutrophils and may be relevant to the pathogenesis of immune neutropenia.

\section{METHODS}

Antineutrophil autoantibodies were obtained from three female patients. Patient A had Myasthenia gravis and neutropenia, patient $B$ had Graves' disease, and patient $C$ had autoimmune neutropenia. All had immunoglobulin (Ig)G autoantibodies that displayed opsonic activity against their own 
neutrophils and against gradient-purified neutrophils of many normal adults (see below). The opsonic activity was expressed in the absence of complement. Sera from patients $A$ and $C$ were tested for activity against previously defined neutrophil antigens (3) and were negative in these agglutination assays (kindly performed by Dr. P. Lalezari). Serum from patient C was tested for anti-HLA activity by standard methods and was negative. (This does not rigorously exclude an HLA antibody that is not lymphocytotoxic.) IgG was purified from the serum by ion exchange chromatography on diethylaminoethyl cellulose, and the purity of IgG preparations was established by immunoelectrophoresis. Some of the IgG from patient $C$ was conjugated with fluorescein isothiocyanate by standard methods (4). Control IgG was purified from pooled normal serum. In some experiments, whole serum (heated for $30 \mathrm{~min}$ at $56^{\circ} \mathrm{C}$ ) was used instead of IgG. With the exception of the fluorescence experiments (which used only purified IgG), each of the experiments described below was performed with both IgG and serum.

Preparation of leukocytes. Human leukocytes, prepared by sedimentation of citrated blood with dextran (Pharmacia Fine Chemicals Inc., Piscataway, N. J.) as previously described $(5,6)$, contained $80-85 \%$ neutrophils and served as the source of cells for most of the experiments in this work. There were no differences between results of experiments performed with cells performed by this method and with neutrophil concentrates ( $>96 \%$ pure) purified on Ficoll (Pharmacia Fine Chemicals Inc.)-sodium diatrizoate gradients. Donors were normal volunteers.

Cell:cell recognition assay for detection of antineutrophil antibody opsonic activity. Antineutrophil antibody opsonic activity was measured by a quantitative assay of cell:cell recognition, as previously described $(2,6)$. This assay is based on the observation that normal neutrophils recognize other neutrophils sensitized with antibody and respond with an increase in glucose oxidation. $2.4 \times 10^{6}$ normal neutrophils were suspended in $0.2 \mathrm{ml}$ of Krebs-Ringer-phosphate medium (KRP), ${ }^{1}$ $\mathrm{pH} 7.4$, and incubated (sensitized) for $30 \mathrm{~min}$ at $22^{\circ} \mathrm{C}$ with 0.4 $\mathrm{ml} \mathrm{IgG} \mathrm{solution} \mathrm{(300-1,400} \mu \mathrm{g}$ protein $/ \mathrm{ml}$ of $0.15 \mathrm{M} \mathrm{NaCl}$ ) or serum. To these cells (designated "test cells") $15 \mathrm{ml}$ of ice-cold $0.15 \mathrm{M} \mathrm{NaCl}$ was added; the suspension was then centrifuged at $200 \mathrm{~g}$ for $5 \mathrm{~min}$, and the cells were then resuspended in $0.2 \mathrm{ml}$ $\mathrm{KRP}$ (this procedure is referred to as "washing"). An equal number of normal neutrophils (designated "indicator cells") were not exposed to antibody. Instead, they were incubated for $60 \mathrm{~min}$ in $0.8 \mathrm{ml} \mathrm{KRP} \mathrm{containing} 100,000 \mathrm{cpm}$ of $\left[1-{ }^{14} \mathrm{C}\right]$ glucose $(56$ $\mathrm{mCi} / \mathrm{mmol} \mathrm{sp}$ act, New England Nuclear, Boston, Mass.). Indicator and washed test cells were then brought together in a total volume of $1 \mathrm{ml}$ of $\mathrm{KRP}$, at a total cell concentration of $4.8 \times 10^{6}$ cells ( $50 \%$ test, $50 \%$ indicator), in sealed polypropylene scintillation vials, with a strip of hyamine-impregnated filter paper inserted through the top. After a 30-min incubation at $37^{\circ} \mathrm{C}, 1 \mathrm{ml}$ of $5 \mathrm{~N} \mathrm{H}_{2} \mathrm{SO}_{4}$ was injected into the reaction mixture and, after another 20 -min incubation, the amount of radioactive $\mathrm{CO}_{2}$ evolved was determined by counting the filter papers in a scintillation spectrometer. The mean of control incubations (test cells sensitized with normal IgG or serum) was defined as $100 \%$ of control activity (5).

This recognition assay was modified to determine the fate of antibodies and their antigens on the cell surface. Test cells were sensitized and washed, but were not directly exposed to normal indicator neutrophils. Instead, they were first incubated at $37^{\circ} \mathrm{C}$ for varying intervals in normal heat-inactivated serum which contained $1.5 \mathrm{mM}$ mannitol. After this interme-

${ }^{1}$ Abbreviation used in this paper: KRP, Krebs-Ringerphosphate medium. diate incubation, the cells were again washed and exposed to indicator cells as described in the standard assay. In some experiments the cells were sensitized again after the intermediate incubation ("resensitization") by a method identical to the initial sensitization. They were then washed and incubated with indicator cells. In certain experiments the ability of cycloheximide to block recovery of antigenicity was investigated. At the completion of the initial sensitization, cycloheximide, at a final concentration of $10 \mu \mathrm{g} / \mathrm{ml}$, was added (this concentration of cycloheximide reduced the incorporation of $\left[{ }^{14} \mathrm{C}\right]$ leucine into acid-insoluble residue of leukocytes by $>90 \%$ ); the same procedures as outlined above were otherwise followed.

Direct immunofluorescence studies. $5 \times 10^{6}$ gradient-purified neutrophils were suspended in $0.4 \mathrm{ml}$ control serum. To these suspensions was added $0.1 \mathrm{ml}$ of fluorescein-conjugated antibody (or fluorescein-conjugated control IgG) at a final concentration of 50-200 $\mu \mathrm{g} / \mathrm{ml}$. After a 30-min incubation at $22^{\circ} \mathrm{C}$, the cells were washed twice. They were then resuspended in normal serum containing $1.5 \mathrm{mM}$ mannitol and warmed to $37^{\circ} \mathrm{C}$. Aliquots were removed at specific intervals, washed, and smeared on glass slides. Smears were then fixed

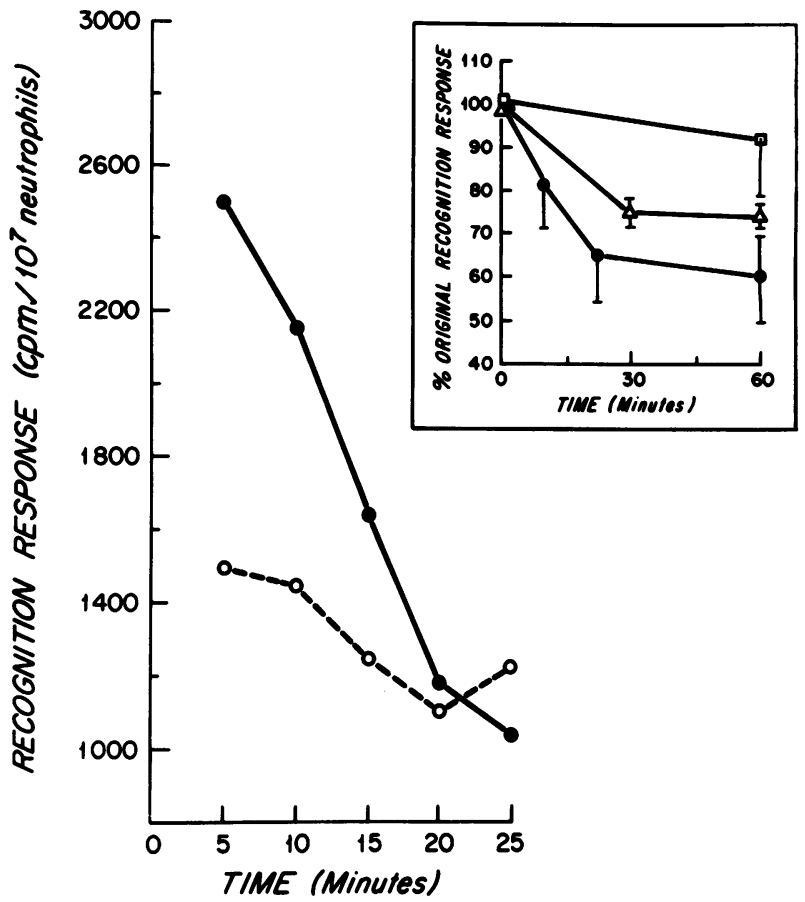

Figure 1 Results of a typical experiment illustrating the time-course of antibody clearance. Antibody-sensitized test cells were incubated at $37^{\circ} \mathrm{C}$ for the times indicated, washed, and exposed to indicator cells (closed circles). The ordinate shows $\left[1-{ }^{14} \mathrm{C}\right]$ glucose oxidation (counts per minute of ${ }^{14} \mathrm{CO}_{2}$ released) by indicator cells. Open circles show parallel control incubations (test cells sensitized with normal IgG). Each point represents mean of duplicate determinations. The insert illustrates the effect of temperature on the time-course. Antibodysensitized test cells were incubated at $4^{\circ} \mathrm{C}$ (upper plot), $22^{\circ} \mathrm{C}$ (middle), and $37^{\circ} \mathrm{C}$ (lower) for the times indicated, washed, and exposed to indicator cells. The ordinate shows percent change in recognition response in glucose oxidation by indicator cells from initial preincubation value. Each point represents mean $\pm \mathrm{SE}$ of two to four duplicate determinations. 
by layering a $1 \%$ solution of paraformaldehyde in $0.15 \mathrm{M} \mathrm{NaCl}$ on the slide for $5 \mathrm{~min}$ at room temperature. They were then gently rinsed, covered with a coverslip, and examined with a Zeiss fluorescence microscope (Carl Zeiss, Inc., New York). Observations were quantified by counting 100-200 cells at each time point.

To determine whether observed fluorescence was intracellular, crystal violet stain $(2 \%$ solution in $0.15 \mathrm{M} \mathrm{NaCl})$ was employed $(7,8)$. This method is based on the observation that crystal violet solutions extinguish fluorescein-labeled compounds when the two substances are in direct contact. Therefore, if the fluorescein-labeled compounds are extracellular, the fluorescence is promptly extinguished when the crystal violet is layered over the cells. However, if the fluorescent label is separated from the crystal violet (i.e., intracellular), it will still be visible despite the addition of crystal violet.

\section{RESULTS}

Loss of opsonic expression from the cell surface (clearance of antibody). Neutrophils sensitized with antineutrophil IgG elicited a recognition response in normal unsensitized indicator neutrophils: $176 \pm 23$ (mean \pm SEM, percentage of control) with $A ; 300 \pm 32$ with $B$; and $191 \pm 27$ with $C$. If the sensitized neutrophils were first incubated in serum at $37^{\circ} \mathrm{C}$ before contacting the indicator neutrophils, the recognition response decayed at a constant rate and was gone after 20-30 min (Fig. 1). Whereas loss of ability to elicit a recognition response occurred within $30 \mathrm{~min}$ at $37^{\circ} \mathrm{C}$, the decay rate was negligible at $4^{\circ} \mathrm{C}$ and intermediate at $22^{\circ} \mathrm{C}$. Clearance sometimes failed to occur if normal homologous or autologous heat-inactivated serum and mannitol were omitted. The requirement for serum and mannitol was not investigated further. However, oxygen metabolites can cause membrane damage to neutrophils that renders these cells recognizable in the recognition assay; mannitol can prevent this secondary membrane damage at concentrations where it has no effect on the standard assay (5). Ingestion of cell-bound antibody theoretically could activate neutrophil respiration sufficiently to create such damage; therefore, mannitol was added.

Immediately after sensitization with fluoresceinated antineutrophil IgG, the cells were diffusely fluorescent (Fig. 2, top left). With incubation at $37^{\circ} \mathrm{C}$, aggregates progressively replaced the diffuse pattern. After 15 $\mathrm{min}, 29 \%$; at $30 \mathrm{~min}, 78 \%$; and at $60 \mathrm{~min}, 88 \%$ of the cells displayed discrete aggregates of the label (Fig. 2, top center). An occasional cell $(<1 \%)$ showed polar "capping" of the label. Clumping or agglutination of cells was not observed. Control cells incubated with fluorescein-labeled nonimmune IgG had a very pale, diffuse fluorescence, and $<10 \%$ of cells examined at any of the incubation times displayed aggregates. Crys-
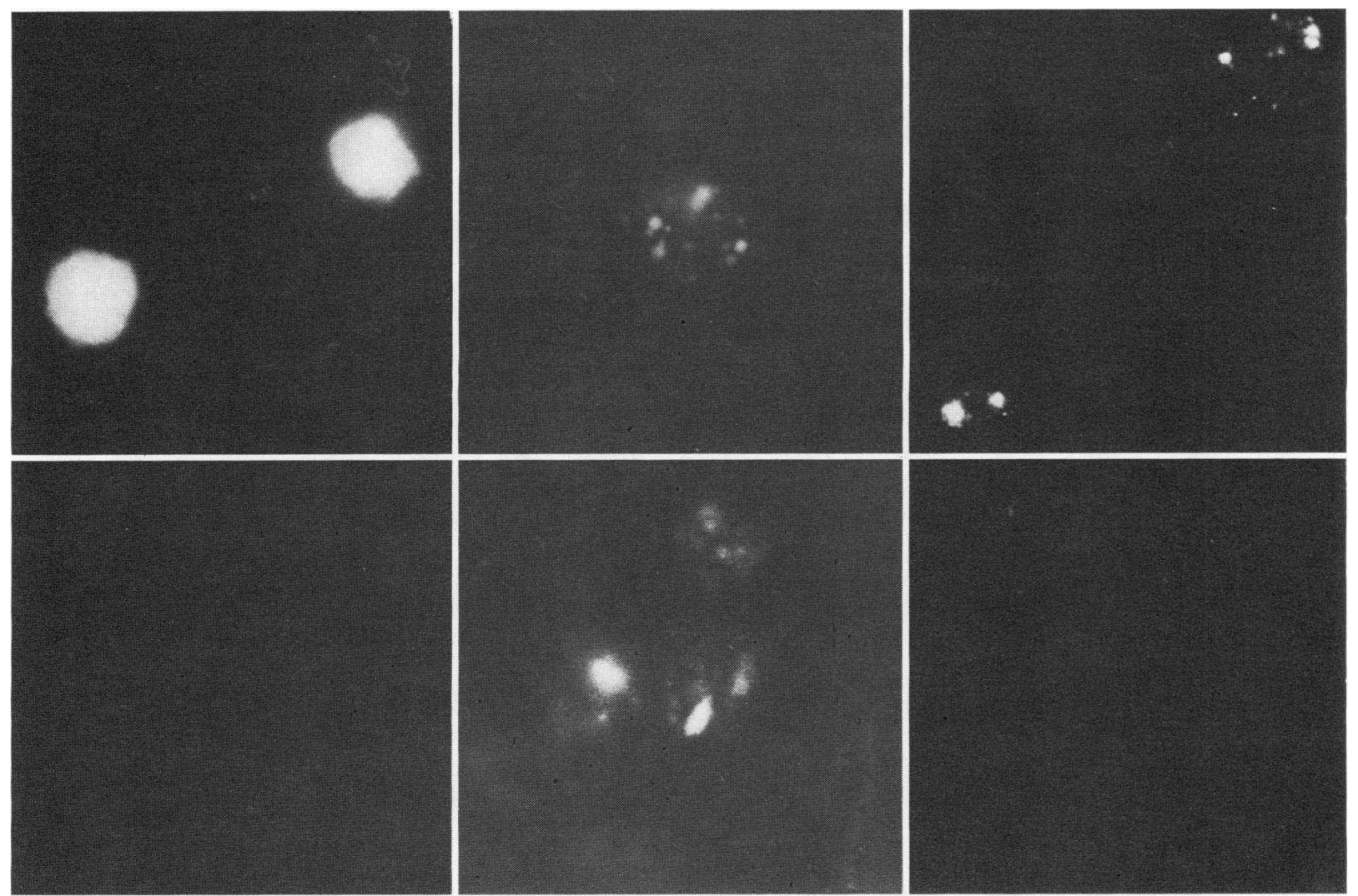

FIGURE 2 Immunofluorescence studies. Top left: neutrophils immediately after sensitization with fluorescent antibody. Top center: cell after 60 -min postsensitization incubation at $37^{\circ} \mathrm{C}$. Top right: Acetone-extracted cells after 60 -min postsensitization incubation at $37^{\circ} \mathrm{C}$. Bottom panels: cells processed exactly as in corresponding upper panels and photographed immediately after covering with crystal violet. 
tal violet promptly extinguished the diffuse fluorescent pattern observed at the completion of sensitization (Fig. 2, bottom left). However, crystal violet did not abolish the aggregates of fluorescence observed in sensitized cells after incubation (Fig. 2, bottom center). After extraction of the postincubation cells by a 5-min exposure to cold acetone (rendering the membrane rapidly permeable to crystal violet), adding the crystal violet solution promptly extinguished this fluorescence (Fig. 2, bottom right), which indicates that the aggregates were intracellular.

Loss and recovery of antigenicity from the cell surface. As neutrophils cleared the sensitizing antibody, they lost the capacity to be sensitized again with the sensitizing antibody (Fig. 3). The time-courses of these processes were similar. Neutrophils incubated under the same conditions but in the absence of antineutrophil IgG remained sensitizable.

If neutrophils which had been sensitized with antibody were incubated at $37^{\circ} \mathrm{C}$ for periods longer than $30 \mathrm{~min}$, the capacity to be resensitized eventually recovered. Fig. 3 illustrates results obtained with the three antibodies. Antigenicity recovered to between 80 and $120 \%$ of the initial value after $90-120 \mathrm{~min}$. Cycloheximide did not inhibit recovery of antigenicity (data not shown).

\section{DISCUSSION}

In this study we investigated the interaction of human antineutrophil autoantibodies with the neutrophil membrane and made the following observations: $(a)$ antibody is cleared from the cell surface by a temperature-dependent mechanism; (b) antigenicity is cleared
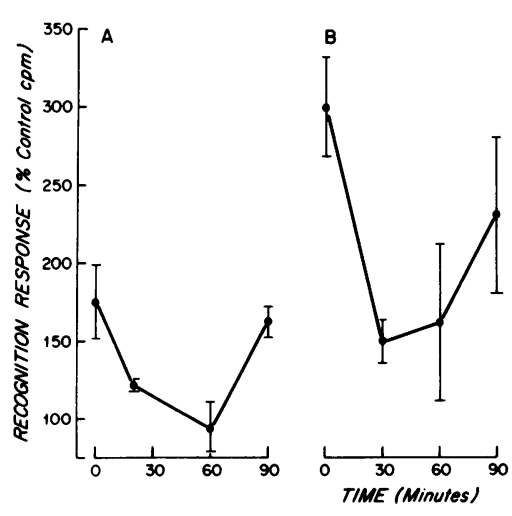

c

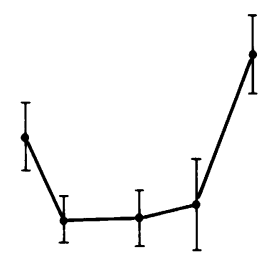

FIGURE 3 Results of resensitization experiments with antibody obtained from three patients. Test cells were sensitized, washed, incubated at $37^{\circ} \mathrm{C}$ for the times indicated, washed, resensitized, and exposed to indicator cells. The ordinate shows recognition response $\left(\left[1-{ }^{14} \mathrm{C}\right]\right.$ glucose oxidation to ${ }^{14} \mathrm{CO}_{2}$ by indicator cells) as percentage of control (recognition response in presence of cells sensitized with normal IgG). Each point represents the mean $\pm S E$ of between 4 and 18 determinations with different cell preparations. concomitantly; $(c)$ the mechanism of clearance involves internalization; and $(d)$ with time, antigenicity reappears on the cell surface.

Our observation that antibody activity is cleared from the neutrophil surface in $20-30 \mathrm{~min}$ at $37^{\circ} \mathrm{C}$ is a consistent feature of the autoantibodies used in this study. The persistent association of the fluorescent antibody with the cell, and the concomitant loss of antigenicity (ability to be sensitized), indicate that this loss of activity was not a result of shedding of antibody. The fluorescent data indicated another mechanism: aggregation and internalization of the ligand during this incubation. It is theoretically possible that this capacity to process antibody might help to protect the neutrophil from recognition and phagocytosis by mononuclear cells in vivo.

Because neutrophils are generally regarded as endstage cells with limited restorative or regenerative capacity, the observed recovery of antigenicity is particularly interesting. Recovery of antigenicity occurred between 90 and $120 \mathrm{~min}$ after the initial sensitization, and this recovery was not blocked by addition of cycloheximide.

Our findings parallel closely observations on the binding, aggregation, and internalization of several well-characterized ligand-membrane systems (9). Additionally, the similarities between our data and the phenomena of antigenic modulation in mouse lymphocytes, and of "down-regulation" of hormone receptors in a variety of cells, are striking $(9,10)$. The biological relevance of hormone-receptor and neurotransmitterreceptor interactions are obvious, but the physiologic significance of membrane antigen turnover in polymorphonuclear leukocytes is unclear. We have suggested that locomotion of neutrophils may require continuous turnover and replacement of membrane moieties and that this replacement could be accomplished by fusion of intracytoplasmic membranes with plasma membrane (11). Because cells must recognize a surface, attach, move, let go, and attach again in a continuous fashion to move, it seems reasonable to postulate some form of continuous receptor turnover as an integral requirement of directed motility.

\section{ACKNOWLEDGMENTS}

We should like to thank Dr. Olle Stendahl for his help with the fluorescence studies.

This study was supported by the Edwin S. Webster Foundation, the Overseas Shipping Group, Inc., a gift of Edwin S. Hiam, and U. S. Public Health Service Research Training grant 1-T32 CA09321.

\section{REFERENCES}

1. Wintrobe, M. M. 1974. Clinical Hematology. Lea \& Febiger, Philadelphia. 910-915, 1077-1079.

2. Boxer, L. A., M. S. Greenberg, G. J. Boxer, and T. P. Stossel. 
1975. Autoimmune neutropenia. N. Engl. J. Med. 293: 748-753.

3. Lalezari, P., and E. Radel. 1974. Neutrophil-specific antigens: immunology and clinical significance. Semin. Hematol. 11: 281-290.

4. Williams, C. A., and M. W. Chase. 1976. Methods Immunol. Immunochem. 5: 424-444.

5. Klock, J. C., and T. P. Stossel. 1977. Detection, pathogenesis, and prevention of damage to human granulocytes caused by interaction with nylon wool fiber. J. Clin. Invest. 60: 1183-1190.

6. Weitzman, S. A., and T. P. Stossel. 1978. Drug-induced immunological neutropenia. Lancet. I: 1068-1072.

7. Hed, J. 1977. The extinction of fluorescence by crystal violet and its use to differentiate between attached and ingested microorganisms in phagocytosis. FEMS (Fed. Eur. Microbiol. Soc.) Lett. 1: 357-361.

8. Stendahl, O., J. Hed, E. Kihlstrom, K. E. Magnusson, and C. Tagesson. 1977. Phagocytic internalization and the requirement for membrane perturbation. FEBS (Fed. Eur. Biochem. Soc.) Lett. 81: 118-120.

9. Kahn, C. R. 1976. Membrane receptors for hormones and neutrotransmitters. J. Cell Biol. 70: 261-286.

10. Old, L. J., E. Stockert, E. A. Boyse, and J. H. Kim. 1968. Antigenic modulation. Loss of TL antigen from cells exposed to TL antibody. Study of the phenomenon in vitro. J. Exp. Med. 127: 523-539.

11. Stossel, T. P. 1978. The mechanism of leukocyte locomotion. In Leukocyte Chemotaxis. J. I. Gallin and P. Quie, editors. Raven Press, New York. 143-160. 